\title{
Performative spaces in the work of Ann Veronica Janssens and Rafael Lozano-Hemmer
}

\author{
Jesús Segura Cabañero \\ Department of Fine Arts, Fine Arts Faculty, University of Murcia, Murcia, Spain \\ Campus Espinardo 30100 Murcia, Spain. \\ Toni Simó Mulet \\ Department of Fine Arts, Fine Arts Faculty, University of Murcia, Murcia, Spain \\ Campus Espinardo 30100 Murcia, Spain.
}

\begin{abstract}
The purpose of this article is to analyze the spatial and temporal relationships in the works of art of Ann Veronica Janssens and Rafael Lozano-Hemmer through the performative. We understand the performative, as a spatio-temporal artistic action that triggers perception, abstraction and political activation. The performative act between the work and the spectator is therefore the essential element of reflection. In the first part, we analyze the decelerated spaces of Ann Veronica Janssens, where the performativity of bodies in spaces and through an ephemeral materiality configures a space in constant transformation. In a second part, we analyze the relational spaces of Rafael Lozano-Hemmer. In his interactive installations, the performative forms an intrinsic part of the work, so that the meeting between the spectator and the work takes place temporarily. Finally, we conclude that these works of art produce a political activation of the environment that proposes the viewer as the true interlocutor who coproduces the work. This work is framed in the new spatio-temporal performativities in contemporary art.
\end{abstract}

Keywords: performativity, space-time, spectator, Ann Veronica Janssens, Rafael LozanoHemmer

\section{INTRODUCTION}

As it is well known, in How to do things with words Austin (1975) defines the concept of performativity in relation to the binomial language-action. However, it will be John Searle (1969) who raises the concept of performativity in its contextual relationship, and more specifically with speech acts. Obviously, the move to a corporal approach of performativity as a relational element of the spatio-temporal construct, and therefore of "social space", understood as a political and ideological space mentioned by Henri Lefebvre (1974), brings about a heated debate about how the construction of what is social is given by different modes of corporeality, of "corpo-politics".

On the other hand, it should be specified for our interests, that "sensory studies" (Bull \& Howes, 2016) consider the sensitive perceptual in a way that is extended to conventional senses. And they propose, as one of their alternatives, to regulate the senses through the body and its movement in space, without mediation of cognitive information. That is why the connection of these incipient ways of exploration with spatio-temporal artistic practices defines what we have called "performative spaces". Developing space-time awareness through perceptive systems, where the senses are implemented with new technologies. These frequencies configure a vast territory of analysis and experimentation where relations of proximity and reciprocity between different disciplines are visualized in current artistic practice. 
We then have a broad body of work, which goes through different disciplines. We find in the spatial performativity or the performative turn, a topological conception of space where a nonrepresentational approach is enabled, formulated by Nigel Thrift (2008) that postulates process, contingent materiality and context of intervention as constitutive elements of a performative geography of space, where the body perceives and constructs it. In this sense, Merleau-Ponty (2002) already attributes to perception a cultural component where the "embodied subject" develops their senses through a construct of social and political meanings.

In this debate we place the works of two artists, such as Ann Veronica Janssens and Rafael Lozano-Hemmer. We analyse their work that becomes of special interest to explore, study and formulate hypotheses around the "vision of the corporal". That is, how the body constructs space and how "acts of seeing" are intimately related to the body's kinesthesia.

At this point, the notion of atmosphere mentioned by Hermann Schmitz (2017) is essential as a way of constructing emotional states. However, we will work here with the notion of an atmosphere developed by Böhme that argues that objects, people or their environments conceive these atmospheres. Without forgetting the reflections of Mieke Bal about the work of Janssens, in which she explain them as a "challenge to the bodily sense of the spectator in relation to the act of seeing" (2016, p. 210), and formulating an interesting reflection about "the political question" in the work of Janssens.

In the same way, Rafael Lozano-Hemmer works with concepts such as "Relational Architecture", technological theatre and artistic performance, incorporating kinesthesia, performativity of the human body and its interaction with the environments it creates in his works. His large-scale urban shows are something between a video installation, a kinetic sculpture and a participatory piece. Another aspect of his work is surveillance, presence/absence, perception/deception or problems of portability and preservation; that accentuate our constant interaction with technology. Inspired by phantasmagoria, carnival and animatronics, he describes his works of light and shadow as "temporary antimonuments for alien agency".

In his theatrical interactive installations in public spaces, it usually deploys new technologies and customized physical interfaces. Using robotics, projections, sounds, Internet and mobile links, sensors and other devices, these installations seek to interrupt the increasingly homogenized urban condition, providing critical platforms for participation.

\section{DECELERATED SPACES OF ANN VERONICA JANSSENS}

Ann Veronica Janssens creates situations that resemble both laboratory experiments and works of art. In this sense, her projects of space immersion evoke the work of James Turrell or Douglas Wheeler. At the same time, the experimental nature of Janssens' work brings us closer to an invisibility, which is proposed with variables of opposites, where transparency-opacity and empty-full dialogue with each other, to articulate confluences towards other realities and imaginary spaces. Transience of the visible reveals spatio-temporal fracture and dissolution of all contingent materiality. In this way, they articulate cognitive forms of space and time where the senses reformulate orientation, gravity, balance, stability, movement, duration, continuity, scale and lighting. These atmospheres awaken an intuitive sensation, a diffuse capture in the viewer where unconscious forms of perception are multi-sensorially activated.

The intention of Ann Veronica Janssens is to provoke an experience of overcoming perceptive limits, delving into abstraction through the use of light and colour arranged in space. And identifying a "political activation" in her work, where immateriality of light is a way of 
subverting institutional contexts and socio-spatial conventions. In her "atmospheres" the viewer undergoes evaluation through the experience with space-time. Blindness, vertigo, deceleration and exhaustion are common sensations that we experience in front of her works. But, without a doubt, if we had to define Ann Veronica Janssens' experiments with a word, this would be -disorientation- that would be given by modification and destruction of space-time and movement of the viewer in that space-time suspension. Where perception, memory and imagination coexist and merge.

Jane Bennett in her book Vibrant Matter (2010) proposes to think of matter as something alive, with qualities that are subject to a specific temporality without a determined hierarchy. The use of light in Janssens creates contingent sensations with architecture and configures diffuse and performative spatio-temporal contexts, generating thus, ephemeral and dynamic experimental fields. Fog is a material of interest to Janssens as a way to give sculptural form to light: "fog produces an experience with contrasting effects. By abolishing all obstacles, materiality, specific resistances to a given context, gives a materiality and touch to the light" (EACC, 2009).

In her work Yellow-Pink-Blue (2015) (fig. 1) visitors who enter that space find it full of artificial coloured fog. The multi-coloured mist that permeates the entire space is in a state of suspension, blurring any detail of surface or depth in space. Fog is so dense that it interrupts the vision and temporarily blinds us. In the meantime, we try to find a visual anchor point. The sense of unreality and temporality are transformed resulting in a spatio-temporal deceleration.

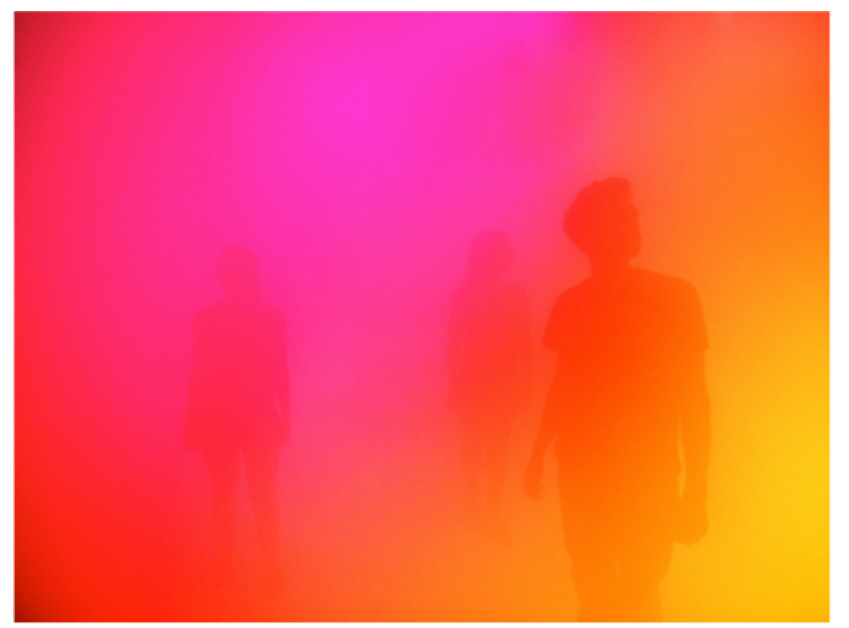

Figure 1. Ann Veronica Janssens, Yellow-Pink-Blue, 2015. (Source:

http://bortolamigallery.com/exhibitions/ann-veronica-janssens-yellowpinkblue/9946/).

Hartmunt Rosa (2013) reflects about the change in the acceleration experience of life, culture and history in which the structural and cultural aspects of our daily practices and our institutions are marked by the "contraction of the present", as a characterization of modern life. These life forms are based on a decrease in experience and are combined with a flow of time in permanent acceleration. All this, results in an acceleration of social and personal processes and perception. Against this, Ann Veronica Janssens proposes that visitors can move through the pavilion in order to experience, not only the deep disorientation caused by the loss of reference points, or the deceleration that occurs in that space-time suspension that she proposes, but also to experience the atmosphere itself as something "haptic", that touches, penetrates and merges with the body. 
In this way, it disables the supremacy of vision subjected to rhythms of production and consumption of accelerated capitalism, for the benefit of haptic multi-sensoriality with a marked political activation. The performativity of bodies in the spaces of Janssens challenges the body's memory through an ephemeral and changing materiality that configures a space in constant transformation. Thus, articulating what Keith Moxey (2013) has called "immaterial time". This immaterial time would be the time that breaks the pre-existing chronologies and enables multi-temporal formations. This embodied knowledge proposed by Ann Veronica Janssens' spaces brings into play processes of spatio-temporal "translation" where, paraphrasing Bruno Latour (2005), an assembly of elements is produced, that constitute themselves as mediators in that spatio-temporal construction. The environment proposes an exchange between materiality and imagination.

We observe a political consciousness in the spatio-temporal distribution, which dialogues with abstraction through atmospheres that disrupt our perception and determine our state of mind. The viewer cannot apprehend the overall space because forms and limits have been suppressed for the benefit of an indeterminate, abstract space. Here, we should bring to discussion Mieke Bal's analysis about the work of Ann Veronica Janssens (2013), since she highlights three aspects in her work: speed, colour and state of mind, as elements that constitute "the political question" in her work, through what Bal calls "Andness" (2013), which would be the attainment of infinity through a denial of all "dominant materiality".

This abstract repetition, in constant process, this "cumulative notion" of abstraction mentioned by Mieke Bal (2013) is constituted as a new process and gives shape to the concept of "Andness". In this way, following Bal we observe that the political question in the work of Janssens occurs in their atmospheres. These are understood as manifestations "conceived by the co-presence of subject and object" (Borch \& Böhme, 2014, p. 45). Establishing, in consequence, a representational structure where confluences of viewer and work define the political activation. This is especially evident in one of her early works, the experience of inhabiting Blue, Red and Yellow (2001) corroborate this. In this work, when light passes through walls and ceilings, mist becomes radiant, saturating its colours and bathing the visitor's body, which is now crossed by a palette of colours, where light and colour assume a semiotic character.

This mimetic strategy defines a space-time environment through luminescent "corpographies", where colour is revealed as an element of difference. And nevertheless, this deferring cannot be captured, since it is in constant transformation, in constant flight, and permanently incorporating the idea of antagonism mentioned by Laclau (2007). In this way, this game of antagonisms recreates the "heterochronic" system as a contingent element. Here, a double movement of fixing-unfixing spatiality and temporality are articulated, and moreover, they cannot be fixed, because there is an excess of signification, embodied in the colour that overflows it. And, consequently, trapped in infinite variables. This is what Laclau (2007) in his concept of antagonism called "discursive" and what Mieke Bal (2013) identifies the convergences that produce political activation.

\section{RELATIONAL SPACES OF RAFAEL LOZANO-HEMMER}

Spatial, technological and architectural peformativities are part of the strategies used by Rafael Lozano-Hemmer in the "Relational Architectures" series. In these, control and surveillance systems are questioned, but a series of debates that involve spatial and architectural contexts in the city and the urban environment are also addressed. Political significance of spaces and architectures in today's globalized cities are represented in the works of Lozano-Hemmer, within the fact of participation that is open to the public that roams 
the city. And it is one of the keys to artistic production in contemporary art, as Lozano-Hemmer himself states: "It is not coincidence that post-modern art emphasizes the audience" (2007, p. 143). This emphasis on public participation is presented as a response or counterprogramming to the progressive isolation of the citizen from his own urban and architectural context. Rafael Lozano-Hemmer reflects about appropriation by power politics and the policies of symbolic representation of architecture and urban space. So, in this way, the artist remarks about architectural and spatial alienation of the city:

Our situation in the globalized city says the opposite: the urban environment no longer represents the citizens it represents capital. Architects and urban developers are build with the priority of optimize cost, and from there to the homogenization of globalization, and from there to the unfortunate reality of contemporary architecture which fetishizes the modular, the formula (Lozano-Hemmer, 2007, p. 146).

Public space no longer represents the citizen and buildings and historical monuments become "vampiric", they substitute the real experience of citizens (Lozano-Hemmer, 2007). Given this dilemma Lozano-Hemmer proposes in his relational works like Body Movies (2001) or Under Scan (2005) a reconsideration of social spaces as non-neutral spaces. In this sense Timothy Druckrey reflects on the relational works of the artist, as:

(...) forms of transitional or experiential "space" and what might be called "haptic" rather than merely "optic" perspectives. "Relational Architecture" reminds us that our social spaces (...) are inhabited by memories of all sorts, that ephemerality is not inconsequential. It is also an architect that will, in Virilio's wonderful phrase, "take place" (2003, p. 70).

Druckrey, following the analysis of Lozano-Hemmer's "Relational Architecture", alerts us of its capacity to transform public space into a space for communication. Proposing that his works favour more a type of assembly than a concentration of a crowd or community. And that his "Relational Architecture": "simultaneously integrates the use of the net as more than a delocalised enclave and reconsiders it as an arena for communication rather than distribution" (2003, p. 70).

The work Body Movies (2001) transforms public space with large-scale interactive projections. Thousands of photographic portraits, which are part of an archive that the artist has previously registered on the streets of the host city, are shown using robotic projectors. In Body Movies Lozano-Hemmer was inspired by seventeenth-century engraving dance shadow of Samuel van Hoogstraten, which depicts actors playing a game of shadow in front of a light source. This piece works by activating portrait photographs when they converge with the projected shadows of the passers-by. The silhouettes can measure between two and twentyfive meters, depending on how near or far they are from the powerful sources of light located on the ground. A video surveillance system activates these portraits continuously and infinitely. This "performative act" occurs when the audience is invited to spatially occupy new narratives of representation. The production of new narratives of representation that break with "official narrative" of public space and institutional buildings, are opened as a possibility, thanks to this interrelation proposed by the piece. Other narratives are produced from play and participation, raising the debate about the dominance of urban public space and urban culture.

As Martijn de Waal says, the piece Body Movies proposes a reflection on advertising and "the invasive commercialization of the public sphere" (2013, p. 64); since the piece makes a replica of advertising design strategies in public space. Thus, converting the spectators in their performance, in their own advertising representation in public space. Body Movies takes place 
in a space where there is a fusion of layers of digital media and physical spaces that are representative of contemporary urban life. This space is called "hybrid space" by De Souza e Silva (de Waal, 2013, p. 64).

Body Movies is one of the examples of Lozano-Hemmer's work in which deployment of digital media creates the possibility of replying the urban public domain with new narratives. These narratives can allude to advertising campaigns, to intimate narratives, with images of "ordinary" people, being photographed during their daily urban routines or simply walking around the city (de Waal, 2013, p. 66). It also reproduces a temporality and a specific spatiality in the interaction of the work where viewers, as Scott McQuire points out:

(...) briefly engage in a playful experience with each other and who discover that they can influence the ambience by performing a collective choreography (...) In short, they are platforms encouraging creative public behaviour, enabling the city to become an experimental public space (de Waal, 2013, p. 69).

Lozano-Hemmer prefers to speak of "Relational Architecture" instead of interactivity, because one of the keys is that collectively many people can participate simultaneously in the work, and thus the mutual interrelation builds the final result of the piece. The relational term refers to this type of "horizontal" and collective participation, where a collection of unexpected "collective patterns" could arise and anticipate (de Waal, 2013, p. 67).

In the same, way we can talk about the "Relational Architecture" of Under Scan (2005) (fig. $2)$. It is an installation on the ground of a public square where archive images taken in Derby, Leicester, Lincoln, Northampton and Nottingham are projected on a human scale, where a robotic detection system introduces them into the shadows of passers-by. When viewers cast their shadows on the ground, the "video-portrait" is revealed and appears in the outline of the shadow, directly questioning the viewers. When it moves away, the video-portrait turns to look elsewhere and disappears. Both Body Movies (2001) as Under Scan (2005) is a proposal to establish an idea of how "we conceive of relations between bodies, identities and built spaces at a time of ubiquitous computing culture" (Ekman, 2012, p. 1). It is the horizontal proposal of the monument idea, or as the artist calls it: "anti-monument".

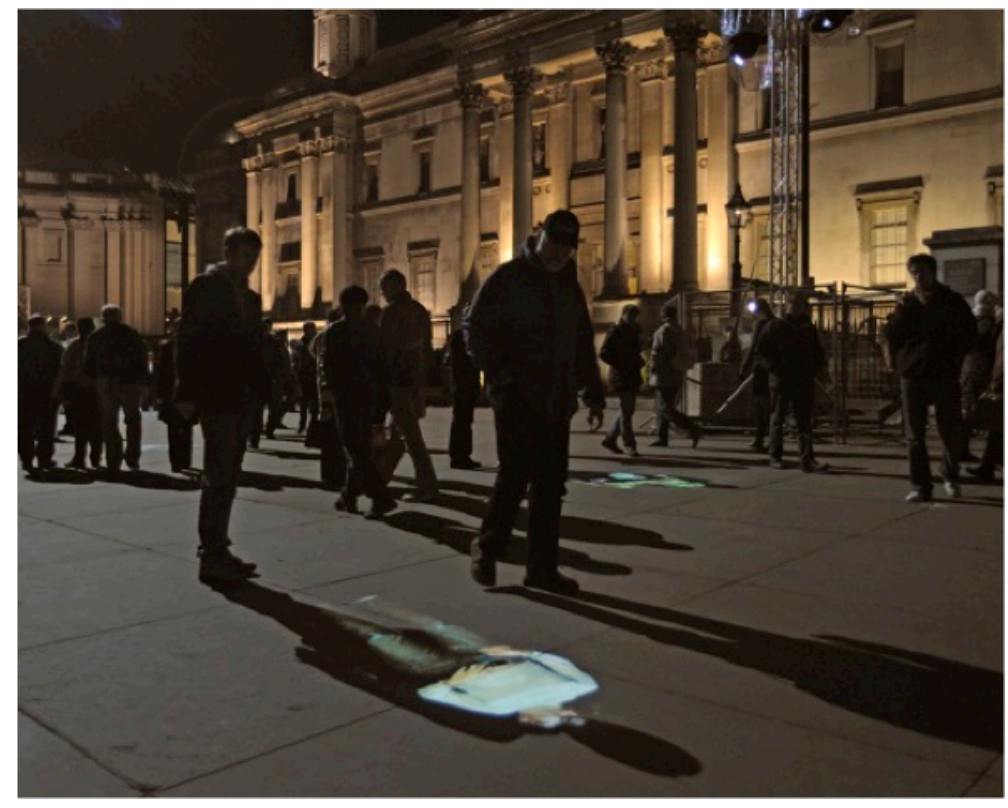

Figure 2. Rafael Lozano-Hemmer, Under Scan, Trafalgar Square, London, 2008. (Source: http://www.lozano-hemmer.com). 
The crisis of representation of public space and public architecture, the disconnection of the citizen from the environment of the globalized city is approached by the "Relational Architecture", in the form of an event of an "interactive" everyday experience. In this way, the work is able to emerge "alien memories" according to the artist's own expression. These memories are those of the spectators, and are alien to the public space itself, but help to create a spatial narrative in a temporary way: "blurring distinctions between outside and inside, private and public, identificatory unity and multiplicity" (Ekman, 2012, p. 8).

The "relational" term refers to the new "temporal relationships" that arise between the spectators and the space of intervention. The "relational" term, therefore, refers to both the spatial relationship and the use of "the temporal" as an artistic strategy to subvert the spacetime given notions of the city. But the space of Lozano-Hemmer works is not designed to function as a "site-specific". They are not designed for a concrete and specific space, but instead the artist is more interested in these relationships that "arise from the artificial situation", which the artist calls "relationship-specific" (Lozano-Hemmer, 2007, p. 146).

\section{CONCLUSION}

Our research explores a body of work that enables what we have called "performative spaces", with the purpose of establishing relations of proximity and reciprocity within the work of Ann Veronica Janssens and Rafael Lozano-Hemmer. Both artists incorporate spatio-temporal registers as a figure of style in their productions. And submit their representations to a spatiotemporal redistribution, which tries to elucidate some of the multiple relations between the spaces and the temporalities that are inscribed in them. The line of argument proposes the spectator as the true mediator, who co-produces the work and activates new perceptive and sensitive experiences and narratives. The dialogue of the body with the environment produces atmospheres and relationships that subvert institutional contexts and socio-spatial conventions.

In all these works we see an idea whose goal is the alteration of the spaces in which we live. As well as the approach of new sensorial and human relationships that try to emphasize the spatial contexts and temporal situations. Thus questioning our perception of the urban and space context and our predictable habits that predominate in our relationship with the environment. Including also the possibility of interrelation between real space and virtual space, with the use of technology and new unexpected materials to form new narratives within cotemporary art.

\section{ACKNOWLEDGEMENTS}

This work is included in the whole of the research proposed by the research project: "The articulated space: contextualizations in contemporary art, spatialties and temporalities in the current artistic production". HAR2015-64106-P (MINECO/FEDER). The paper is funded by the "Programa Estatal de Fomento de la Investigación Científica y Técnica de Excelencia, Proyectos de I+D, del Ministerio de Economía y Competitividad" of the Government of Spain.

\section{References}

Austin, J. L. (1975). How to do things with words. Oxford: Oxford University Press.

Bachelard, G. (1994). Poetics of space. Boston: Beacon Press.

Bal, M. (2013). Endless Andness: The politics of abstraction according to Ann Veronica Janssens. London: Bloomsbury.

Bal, M. (2016). Tiempos trastornados: Análisis, historias y políticas de la mirada. Madrid: Akal.

Bennett, J. (2010). Vibrant matter: A political ecology of things. Durham: Duke University Press. 
Borch, C., \& Böhme, G. (2014). Architectural atmospheres: On the experience and politics of architecture. Basel: Birkhäuser.

Bull, Michael, \& Howes, David. (2016). Editorial: The expanding field of sensory studies. The Senses and Society, 11(1), 1-2. doi: 10.1080/17458927.2016.1194612

Druckrey, T. (2003). "Relational architecture: the work of Rafael Lozano-Hemmer”. Media/Art/Public Domain. Amsterdam: De Balie, Centre for Culture and Politics, pp. 69-72.

EACC (2009). Ann Veronica Janssens, Are you experienced? http://www.eacc.es/es/ann-veronica-janssens/ (Retrieved 15th january 2018).

Ekman, U. (2012). "Of the untouchability of embodiment I: Rafael Lozano-Hemmer's Relational Architectures". CTheory, pp. 6-19.

Janssens, A. V. (2015) “Micheline Szwajcer, Ann Veronica Janssens”. http://www.gms.be/index.php?content=artist_detail\&id_artist=29. (Retrieved 7th january 2018).

Laclau, E. (2007). Emancipation(s). London: Verso.

Latour, B. (2005). Reassembling the social: An introduction to actor-network-theory. Oxford: Oxford University Press.

Lefebvre, H. (1974). La production de l'espace. L'Homme et la société, 31(1), 15-32.

Lozano-Hemmer, R. (2007). Some things happen more often than all the time. Madrid: Turner.

Merleau-Ponty, M. (2002). Phenomenology of perception. London: Routledge.

Moxey, K. P. F. (2013). Visual time: The image in history. Durham: Duke University Press.

Rosa, H. (2013). Social acceleration: A new theory of modernity. New York: Columbia University Press.

Schmitz, H. (April 27, 2016). “Atmospheric spaces”. Ambiances. http://journals.openedition.org/ambiances/711. (Retrieved 14th january 2018); DOI: 10.4000/ambiances.711

Searle, J. R. (1969). Speech acts: An essay in the philosophy of language (Vol. 626). Cambridge, UK: Cambridge University Press.

Thrift, N. J. (2008). Non representational theory: Space, politics, affect. London: Routledge.

Waal de, M. (2013). “Body Movies: The city as interface”. In, Thissen, J., Zwijnenberg, R., \& Zijlmans, K., Transformations in art and culture. Amsterdam: Amsterdam University Press, pp. 62-71. 